\title{
ЭКСПЕРИМЕНТАЛЬНОЕ ПСИХОЛИНГВИСТИЧЕСКОЕ ИССЛЕДОВАНИЕ ПОНЯТИЯ КӨНҮЛ (СВОБОДА)
}

\section{EXPERIMENTAL PSYCHOLINGUISTIC STUDY OF THE "KӨHYL» (FREEDOM) IN THE MINDS OF YAKUT STUDENTS}

\section{Z. Adamova \\ D. Chirkoeva}

Summary: This article is a continuation of the presentation of the results of psycholinguistic analysis of experimental data on the axiological concept of «көнүл» (freedom), and aims to reveal the national-cultural specificity of meaning associated with the need for «көнүл» (freedom). To this end, it provides an analysis of the structure and content of the psychological meaning of the value of «kөнүүl» (freedom) in the Yakut language in comparison with a similar structure of «freedom» in Russian. As a result, based on the analysis, we have identified a common and specific role of the analyzed concepts in the life of the subjects.

Keywords: көнул (freedom), verbal reactions, speech operations, speech actions, personal meaning, motivational relevance.
Адамова Зоя Гаврильевна

к.фрилол.н., Московский государственный лингвистический университет

zoya_adamova@mail.ru

Чиркоева Дария Ивановна

к.филол.н., дочент, Северо-Восточный федеральный университет имени М.К. Аммосова dchirkoeva@mail.ru

Аннотация: Данная статья является продолжением представления результатов психолингвистического анализа экспериментальных данных по аксиологическому понятию свобода, и имеет цель выявить национально-культурную специфику смыслообразования, связанного с потребностью көнүул (свобода). Для этого в ней приводится анализ структуры и содержания психологического значения ценности көнүул (свобода) на якутском языке в сравнении с аналогичной структурой свободы на русском языке. В результате на основе анализа выявлены общее и специфическое в побудительной роли анализируемых понятий в жизни испытуемых.

Ключевые слова: аксиологическое понятие көнүүл (свобода), ассоциативный эксперимент, личностный смысл, речевые операции, речевые действия, мотивационная значимость.

Личностный смысл является элементом концептуальной системы, которая, по В.А. Пищальниковой, представляет собой континуальную систему смыслов, структурирующуюся в деятельности индивида в результате присвоения а) конвенционального опыта, б) перцептивных процессов, в) собственно рефлексии [8]. В структуре интегративной модели концепта выделяются тело знака, понятие, представление, предметное содержание, эмоции и оценки, а также специфическая группа признаков, условно названная «другие ассоциации». При этом под представлениями понимаются субъективные чувственные образы действительности, зависящие от индивидуальных особенностей: опыта, возраста, научной подготовки и т.д.; понятие представляет совокупность наиболее существенных признаков предмета, явления; предметное содержание отражает вовлеченность предмета, явления в какой-либо вид деятельности; эмоция и оценка выражают определенные чувства индивида и положение предмета, явления на субъективной шкале «хорошо-плохо»; другие ассоциации - это единичные ассоциации, которые однозначно не интерпретируются с помощью известных культурных и лексикографических знаний [Там же].

\section{Хом исслеАования}

Оптимальным для психолингвистического анализа ценностей нам представляется модель актуального личностного смысла [8]. \section{анализа \\ Методы и параметры психолингвистического}


ление реакций по категориям было основано на понятийных признаках свободы, запечатленных в словарном определении көнүл (свобода) [6]. Согласно задачам нашего исследования, мы рассматриваем эту группу реакций общественно-исторического характера как «объективную» и используем ее как базу для интерпретации функциональной связи между стимулом и реакцией, так как «здание смысла» (Л.С. Выготский), который мы моделируем, строится из значения слова. Другая группа «объективных» реакций представлена воспроизводящими встроенных в систему вербальных ассоциаций индивида, не связанные с мотивом деятельности, автоматические ассоциативные связи между стимулом и реакцией, которые составили $17 \%$ от общего количества реакций (271 реакция из 1223). При этом $71 \%$ автоматических реакций - это речевое действие «көнүл-босхо» (151 реакция), которая реализует понятийный компонент значения анализируемого понятия көнүл-босхо / беспрепятственно, без каких-либо ограничений. Другие речевые действия в содержании данного компонента представлены частотными и единичными автоматическими реакциями: олох (свободная жизнь), тустуу (вольная борьба), свобода и другие.

Затем мы выделили в отдельную группу реакции эмоционально-оценочного характера (всего 299 реакции) и определили модальность анализируемых реакций по двум диалектически единым, но содержательно разным побуждениям в виде стремления и удовлетворения, с одной стороны, разочарования и неудовлетворения, с другой стороны [2]. Структура эмоционально-оценочного компонента в результате анализа выглядит следующим образом:

1. Положительная эмоция и оценка (102): дьол (счастье) 40; үөруү (радость) 20; үчүгэй (хороший, хорошо) 8; күндү (дорогой) 6; сырдык (светлый) 5; ыраас (чистый) 5; биһиэхэ күндү (дорогой для нас) 4; күүс (сила) 4; саамай күнду (самый дорогой) 2; бэһиэлэй (веселый); ордук (лучше); саамай ордук (наилучший); сөбүлэтэр (имеет свойство нравиться); состояние эйфории; счастье; биһиги кэскилбит (наше будущее); итэқэйэбин (верю).

2. Утверждение, что свобода есть (7): баар (есть) 5; элбэх (много) 2.

3. Утверждение, что свободы нет (4): суох (нет, не существует) 2; киһиэхэ суох (у человека нет, не существует); быраһаай (прощай).

4. Побуждение к действию с положительной модальностью (9): буол (будь) 2; үөр (радуйся) 2; харыстаа (береги) 2; барыах (освободимся); босхолон (освободись); тосхойдун (пусть будет послано, улыбнется).

5. Побуждение к действию с отрицательной модальностью (2): сылдьыма (не будь; не ходи); бырах бар (выбрось).

6. Отрицательная эмоция и оценка (6): бардам (на- глый); беспредел; лох; куттааһын (имя действия пугать), халява, харана (темнота, темный).

7. Сомнение (реакции билбэппин (не знаю) и ким (кто) и отказ (169) с положительной модальностью. Несмотря на сложившуюся традицию рассматривать отказ от ассоциирования как свидетельство о неактуальности исследуемого понятия в концептуальной системе респондента, мы с учетом специфики анализируемого понятия көнул (свободы) вслед за В.В. Бибихиным в своем анализе интерпретируем отказы как «молчание», основа которого «вносит разрыв между словарным значением и действующим смыслом слова», в который «кроме значения входит то, что оно сказано, когда его могло и не быть» [4] и рассматриваем их как выражающие скорее значимость свободы, чем наоборот.

Далее, мы определили направленные на способы осуществления потребности речевые операции (369). В соответствии с деятельностным подходом к сознанию осознание целей действия может быть проявлено в «другой стороне целеобразования, которая состоит в конкретизации целей, выделении условий, в которых она (цель) дана» $[7$, с. 15]. Выделение этого собственно действенного параметра является решающим в нашем исследовании, так как осознанное отношение к потребности, предполагающее определенную направленность личности, ориентирующую ее избирательную активность, ведет к поиску «субъективных» средств и условий ее реализации. Эту направленность мы можем обнаружить в операциях.

Операции - способы осуществления действий, «как правило, вырабатываются, обобщаются и фиксируются общественно-исторически, так что каждый отдельный индивид обучается операциям, усваивает и применяет их» [7, с. 15]. «Продукт действия» по своему происхождению, «исторически - продукт общественной практики», операция зависит от условий достижения целей, но если ее рассматривать изолированно от деятельности человека, «выступает как процесс непсихологический». Однако «системный и генетический анализ открывает их (операции) как осуществляющие деятельность психологическую» [7, с. 12]. Для того, чтобы понять, какую психологическую роль играют социально обусловленные речевые операции на деятельность наших испытуемых, мы выявили и распределили речевые действия, осуществляющие операциональную связь между стимулом и реакцией, в группы по семантическим признакам инвариантного значения слова көнүл (свобода).

Значительная часть речевых операций на якутском языке так же, как и на русском языке [1], связана с понятийным компонентом, которому мы дали название «Природа». В словарной дефиниции понятия көнүл (свобода) 
данный компонент представлен двумя устойчивыми образными выражениями: «көнүл көт» (быть вольным как птица) и «көнүл тыын» (вздохнуть свободно, почувствовать облегчение). Другие частотные речевые операции, выраженные, в основном, отглагольными именами действия, реализуют связь со следующими понятийными компонентами: 2) с устойчивым словосочетанием көнүл ыыт (ослабить требовательность, отпустить или распустить кого-либо) и близким к нему босхолоо (отпускать на волю, освобождать); 3) с разговорным выражением көнүл көрулээн (привольно, вольготно жить); 4) калькой көнүл арыыта (остров свободы) и другими «символами свободы»:

1. «Природа» (148): тылал (ветер) 19, халлаан (небо) 18, чыычаах (птица) 17, наБыл (тихий, спокойный) 14; көтүу (полет) 10, салгын (воздух) 9, алаас (алас) 6, көтөр (птица) 4, киэн (просторный, широкий) 3; сир (земля) 3, күөл (озеро) 2, күн (солнце) 2, кынат (крыло) 2, сөруүн салгын (прохладный воздух) 2, тыын (дыхание) 2, хонуу (поле) 2, хотой (орел) 2, ыраас халлаан (чистое небо) 2, ыраах (далеко) 2; айыльа (природа), аһақас (открытый, просторный), бөрө (волк), дай (разбегаться, размахивать крыльями), дайдарыы (имя действия от размахивать крыльями), истиэп (степь), киэн алаас (широкий алас), көтөр кыыл (птица), куйаар (пустыня), күөх (зеленый), күөх от (зеленая трава), кыыл (животное), лыах (бабочка), муора (море), ойуур (лес), өрө тыыныы (вздох), поле, полет, сайын (лето), сыгынньах атах (босиком), сыһыы (долина), тайaх (лось), тыл (лес), хоту (север; считается, что в природе на севере много простора), ыраас салгын (чистый воздух), ырааһыйа (поляна), эйгэ (среда, окружение).

2. «Процесс отпускания и пребывания на воле; освобождение» (67): босхолонуу (имя действия глагола возвратно-страдательного залога освобождать себя) 20; босхо барыы (имя действия освобождаться, отвязываться) 10; босхолооһун (имя действия освобождать) 3; босхо бар (освобождаться, отвязываться) 2; босхо буолуу (имя действия быть непривязанным, свободным) 2; босхо сылдыыы (имя действия ходить свободно) 2; босхолоо (отпускать на волю, освобождать); босхолонооһун (имя продолжающегося действия освобождаться); барыы (имя действия отправляться) 12, бар (отправляться, идти) 3, барда (результат действия отправляться) 3, барааһын (имя действия возвратно-страдательного залога отправляться, идти) 3, барар (отправляется) 2, барбыт (отправился), барбыт киһи (отправившийся человек), ыытыы (имя действия отпустить).

3. «Гулянье, веселье» (61): күүлэй (гулянье) 34, көрул (искаженное от көрүлээн / вольготно) 5; күүлэйдээһин (имя действия гулять) 4, бырааһынныык (праздник) 3, көччүйуү (имя дей- ствия резвиться, веселиться) 3, нар (көр-нар/ веселье) 3, арыгы (вино), дьаарбайыы (прогулка), гулять, көр (көр-нар/ веселье), көрсүу (встреча, свидание; любовник), көөчүк, көччүй (резвиться, веселиться), күүлэйдии (имя действия гулять), күүлэйдээ (гулять).

4. Символы свободы (7): былаах (флаг) 3, холууп (голубь) 2, манан (белый), статуя.

Далее мы выявили речевые операции, связанные с понятийным компонентом понятия на русском языке свобода - «незанятое время, досуг» (всего 22 реакции): таһырдьа (снаружи, на улице) 3, дьиэ (дом) 2; иллэн (незанятый) 2, каникулы 2, сынньалан (отдых) 2, ыраах (далеко) 2, бокуой (покой), вечер, дьиэттэн тэйии (имя действия уходить, отдаляться от дома), киэһэ (вечер), уоскуйуу (успокоение), уулусса (улица), утуйуу (сон), улэтэ суох (без работы), туүн (ночь).

Наконец, выявленное нами специфическое для речевых операций на якутском языке (64) содержание связано с такими способами реализации потребности в көнүл, как:

1. Владение собой и утрата способности владеть собой (20): бэйэни көрунуу (имя действия глагола возвратно-страдательного залога смотреть, ухаживать за собой), туттуу (имя действия глагола возвратного залога строить, держать себя); най барыы 3 (имя действия отбиться от рук), ahapa барыы (имя действия переходить граниuы), бас барыы (имя действия обезуметь), босхо барбыт төбө (голова без забот), бэйдиэ сылдыыы (имя действия ходить бесцельно), мээнэ (попусту, бессмысленно), мээнэ-мээнэ (попусту, бессмысленно), мэнээк (попусту, бессмысленно), мэник (глупый, шаловливый), мээнэ барыы (распустить себя), мээнэ сылдыыы (ходить бесцельно), най (бесцельно), таах мээнэ (попусту, бессмысленно), тутула суох (без тормозов, границ), тутулун суох буолуу (имя действия быть без тормозов, границ), ыhыктыныы (имя действия не владеть собой).

2. Постоянство и обычность действия (17): сылдьыы (имя действия вспомогательного глагола сырыт / ходить, двигаться, пребывать) 5, сырыт (ходить, пребывать) 4, сылдьар 4, сырыы 2, босхо сылдьар (ходит, пребывает свободно); тугу эрэ гынааһын (имя продолжающегося действия делать чтолибо).

3. Процесс активной деятельности (14): харчы (деньги) 3, дыыала (дело) 2, дьарык (занятие), улэ (работа), кыайыы (победа), күрэхтэһии (состязание, соревнование), оонньооһун (играть), сүүр (бежать), сүуруу (бег), хаамыы (ходьба), харбыы (плавание).

4. Достижение совершеннолетнего возраста, взросление (8): улаатыы (рост, взросление) 2, улахан киһи оло5ор хардыы (шаг во взрослую жизнь), 18, о5олор (дети), саас (возраст), саас туолуу (дости- 
жение возраста), эдэр саас (молодость).

5. Образование, рост (5): уөрэнии (обучение), өйдөнуу (имя действие от образумиться), ситиhuи (успех), суол (путь, дорога), уөрэбэ суох киһи (необразованный человек).

Другой особенностью содержания ассоциативного значения көнүл является смыслообразование «субъективных» представлений, не связанных с его понятийными компонентами. Так, 108 речевых действий, то есть $74 \%$, в анализируемом компоненте (145), реализуют связь с творчеством: боотурдар (у древних якутов: человек большой физической силы, воин) 47, боотур 44, ырыа (песня) 10, арчы (обряд, ритуал), көнүл боотурдар, тойук (народная песня-импровизация), саарын (фолькл. саха саарына - лучший, самый достойный, народный лидер), уолаттар (молодые люди), хоһоон (стихотворение), ыhыах (ысыах - национальный якутский праздник). Наиболее частотные реакции боотурдар (у древних якутов: человек большой физической силы, воин) 47, боотур 44 и другие, по сути, не относятся к собственно фольклорным явлениям, а обусловлены общественным событием - выходом в 2010 году фильма-комедии в стиле исторической легенды под названием «Көнүл боотурдар» («Вольные ботуры»). Следующую группу представляют речевые действия, которые, в отличие от первой, на наш взгляд, выражают личностную значимость анализируемого понятия. Дело в том, что они не связаны с «объективными» значениями и, по всей видимости, исходят из этимологии анализируемого понятия: көнгл происходит от пратюркского göjn-il и древнетюркского könӥl - сердце, душа; дух. В такой интерпретации мы находим особую привлекательность, так как именно в этих речевых действиях, возможно, обнаруживается «идеальное», по М. Хайдеггеру, значение көнүл, близкое к специфике личностной ценности - «идеальной модели должного», по Д. Леонтьеву: санаа (мысль, желание) 14, ыраас санаа (чистое, искреннее желание, мысль) 2, дууһа (душа) 2, өйдөө (понимать, помнить). С данным выявленным в речевых действиях «идеальным» содержанием, очевидно, связаны и «субъективированные», обнаруженные в речевых действиях, характеристики көнүл, такие, как случайность (араас, билгэ, быстах, түгэн), одиночество (со5отохсуйуу, со5отох) и любовь (таптал). Отметим, что такие же «субъективированные» черты свободы были обнаружены в содержании структуры ассоциативного значения понятия свобода. По нашему мнению, выявленные общие по содержанию особенности «субъективированных» представлений выражают значимость обоих проанализированных понятий как личностных ценностей, так как они связаны не своим обобщенным значением, а наоборот, особенным «всечеловеческим» содержанием. Как пишет В. В. Бибихин, «в качестве общей основы слова любого частного языка, значительности (курсив наш - 3.А.), существует всечеловеческий язык», который и является залогом человеческого понимания [4, с. 175].

\section{Результаты исследования}

Итак, представим структуру психологического значения көнгл, а также для демонстрации тенденции дина-

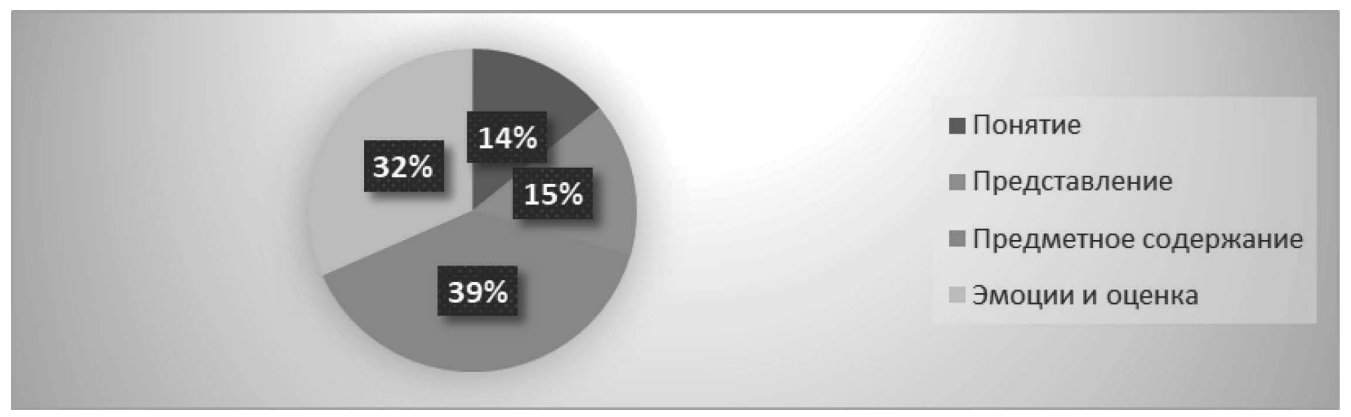

Диаграмма 1. Модель структуры личностного смысла көнүл

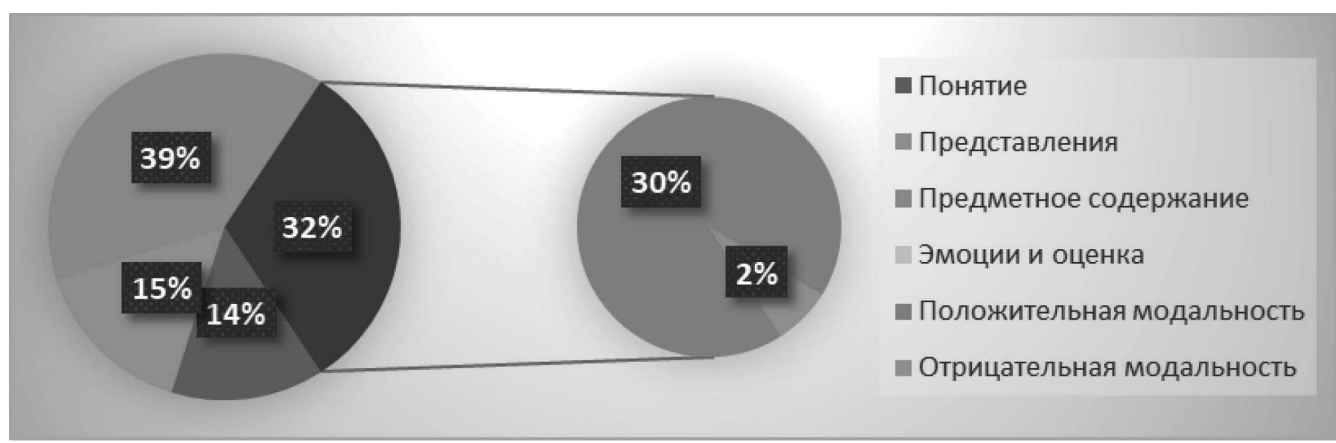

Диаграмма 2. Модель структуры личностного смысла көнүл с двумодальной структурой эмоционально-оценочного компонента 


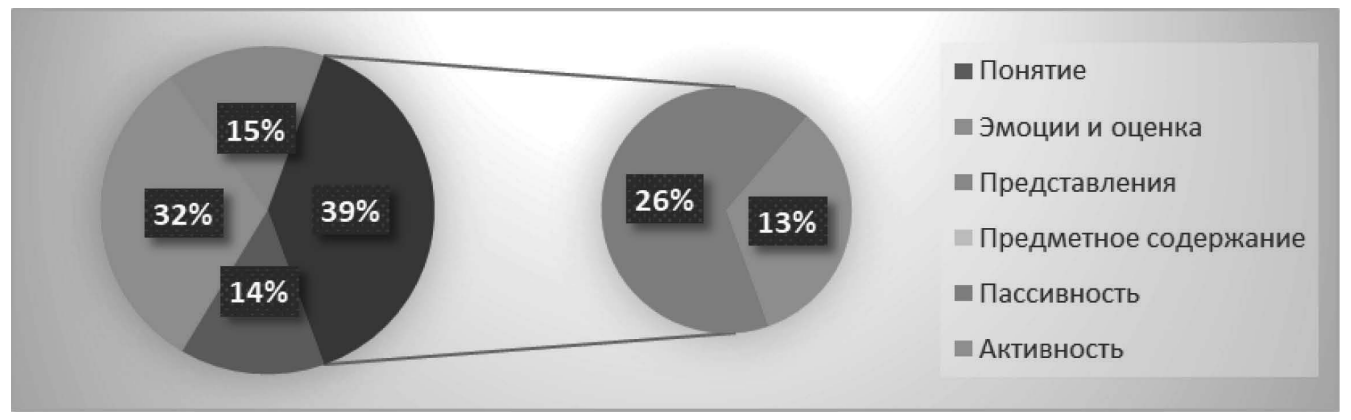

Диаграмма 3. Модель структуры личностного смысла көнүл

с двумодальной структурой действенного компонента

мической стороны потребности в көнгл - полученную структуру с двумодальными структурами эмоционально-оценочного и действенного компонентов.

Содержание эмоционально-оценочного компонента говорит о значимости анализируемого понятия: 92\% речевых действий говорят о значимости потребности в көнүл, однако отметим, что $61 \%$ из них при этом - это отказ от ассоциирования. Другие 8\% выражают противоречивые эмоции «активно-действенного» характера, связанные с неудовлетворенностью потребности, с одной стороны, и с предостережением и негативной оценкой, с другой стороны. В эмоциональные речевые действия активного характера мы включили также такие побуждения к действию положительной модальности, как буол (будь) 2; үөр (радуйся) 2; харыстаа (береги) 2. Специфическое речевое действие эмоционального характера тосхойдун (пусть будет послано, улыбнется), на наш взгляд, должно быть интерпретировано с особым вниманием. Дело в том, что данное речевое действие Көнгул тосхойдун! (в буквальном переводе: Да будет послано! или Да улыбнется свобода!), если пытаться связать его с «объективными» значениями понятия көнүл, представляется лишенным смысла. Однако оно обретает смысл, если мы посмотрим на этимологию анализируемого понятия: көнүл происходит от пратюркского gӧjnil и древнетюрского könӥl - сердце, душа; дух. Именно этим «идеальным» значением, возможно, объясняется «молчание» молодых респондентов - большое количество отказов от ассоциирования в данном компоненте. Ведь «молчание иногда говорит весомее слова» и отвечает по-настоящему «значительному», «неопределимому в мире» [4, с. 161].

Более того, эту же функциональную связь со «значительным», мы обнаруживаем в содержании действенного компонента - направленной на чувственное ощущение природы или чего-то еще более «неопределимого» динамике. Однако, в содержании действенного компонента психологического значения көнүл, в отличие от проанализированной нами структуры ассоциативного значения понятия свобода [1], актуализирован также преобладающий активный компонент, который находит свое выражение в эмоциях предостережения, а также в наиболее частотном автоматизированном речевом действии «көнул-босхо» - имеющем пежоративную коннотацию наречия «без ограничений, границ». Речь идет о смыслообразовании на основе понятийного компонента «көнүл ыыт» (отпускать на волю, освобождать) и связанного с ним «көнүл бар» и «көнүл көрулээ» (освобождаться, быть без забот). Эта внутренняя форма понятия көнүл и определяет актуальную динамику потребности в көнүл. С точки зрения психологии личности, динамика в потребности такого содержания не выражает личностного к ним отношения. С другой стороны, эта же форма көнүл определяет характер небольшого количества «субъектных» речевых операций, связанных с владением собой и ростом.

\section{Зак^ючение}

Мы выявили актуальный для наших испытуемых характер обращения с таким важным понятием как көнүл (свобода) в своей жизнедеятельности. Как видим, безобидное когда-то значение с пометкой разг. играет на самом деле важную психологическую роль и определяет практическое поведение, связанное со словом көнүл, которое трудно назвать волевым, как раз наоборот. Мы обнаружили также и «идеальное» значение көнүл, которое определяет устойчивую мотивацию и на основе которого образованы выявленные нами смыслы личностной ценности. Мы полагаем, что сопоставительный психолингвистический анализ характера и содержания речевых операций и действий, связанных с аксиологическими понятиями свобода и көнүл, позволил нам обнаружить не только национально-культурную специфику смыслообразования, но и общий «особенный всечеловеческий язык», свойственный личности. Как метко определяет В.В. Бибихин, «объединяет людей не обобщенное, а особенное» [4, с. 175]. Выявленные нами особенности характера обращения с аксиологическими понятиями свобода и көнүл имеют отношение к двум важным с точки зрения изучения социальной структуры общества элементам. Согласно утверждению Роберта Мертона, интегрированные в культуру и «включающие в себя различные степени престижа и эмоции» 
цели или устремления общества, с одной стороны, и одобряемые и регулируемые обществом способы достижения этих целей, с другой, обусловливают способы «приспособления или адаптации» человека к обществу [9, с. 28]. Как показывают результаты нашего исследования , «обобщенный» характер ценности свобода устремлен на достижение так называемых ценностей гуманизма как философского направления, таких как неприкосновенность естественных прав человека на жизнь и счастье, выбор и рациональность, распоряжение своей жизнью, развитие всех людей с равными правами, а также на борьбу против политического гнета [1]. При этом мотивационная значимость культурных представлений такого характера определяется главным образом чувственным ощущением природы или «чего-то большего» и в меньшей степени стереотипными представлениями о символах свободы. Других приемлемых способов достижения присвоенных намерений, связанных с личной и политической свободой, российские студенты не знают (не умеют) [Там же]. В отличие от них якутские студенты присвоили в первую очередь противоречивый характер көнүл (свобода), находящий свое выражение в содержании общих эмоций, и связанный со стремлением к вольной (как у птицы) жизни, а с другой стороны - освобождением от ограничений в жизни. Приемлемыми способами достижения такой ценности как көнул они видят созерцание окружающей среды, а также работу над собой, но, к сожалению, наиболее «престижным» средством им представляется беззаботная и веселая жизнь. Мы убеждены, что обнаруженные нами особенные для русской и якутской лингвокультур социокультурные цели, связанные с аксиологическими понятиями свобода и көнгл, и способы их достижения требуют осмысления с социологической точки зрения, а общие, свойственные личностным ценностям свобода и көнүл, лингвокультурные представления нуждаются в нашей защите, так как они принадлежат хрупкому языку Мира.

\section{ЛИТЕРАТУРА}

1. Адамова 3.Г., Чиркоева Д.И. Неосознанная необходимость, или содержание понятия свобода в сознании российских студентов // «Современный ученый» №5. 2021. URL: http://su-journal.ru

2. Асеев В.Г. Мотивация поведения и формирование личности. М.: Мысль, 1976. 158 с.

3. Ассоциативный словарь якутского языка URL: http://adictsakha.nsu.ru/dict (дата обращения сентябрь 2020).

4. Бибихин В.В. Мир. Язык философии. СПб.: Азбука, Азбука-Аттикус, 2016. 448с.

5. Леонтьев А.Н. Деятельность. Сознание. Личность [Электронный ресурс: URL: http://www.psy.msu.ru/people/leontiev/dsl/3-2.html] (дата 0бращения 01.11.20)

6. Толковый словарь якутского языка = Саха тылын быһаарыылаах тылдьыта: Т.4. Новосибирск: Наука, 2004. 572 с.

7. Основы теории речевой деятельности. М.: Наука, 1974. 333 с.

8. Пищальникова В.А. Концептуальный анализ художественного текста: учебное пособие. Барнаул, 1991. 87с.

9. Кризис сознания: сборник работ по «философии кризиса». М.: Алгоритм, 2009. 272 с. 